\title{
Programmable Smart Home Toolkits Should Better Address Households' Social Needs
}

\author{
Antti Salovaara \\ Aalto University, Department of Design and \\ University of Helsinki, Department of Computer Science \\ Finland \\ antti.salovaara@aalto.fi \\ Andrea Vianello \\ Aalto University, Department of Computer Science \\ Finland \\ andreavianello@gmail.com
}

\begin{abstract}
End-user-programmable smart-home toolkits have engendered excitement in recent years. However, modern homes already cater quite well to users' needs, and genuinely new needs for smart-home automation seldom arise. Acknowledging this challenging starting point, we conducted a six-week in-the-wild study of smart-home toolkits with four carefully recruited technology-savvy families. Interleaved with free toolkit use in the home were several creativity workshops to facilitate ideation and programming. We evaluated use experiences at the end of the six weeks. Even with extensive facilitation, families faced difficulties in identifying needs for smarthome automation, except for social needs that emerged in all the families. We present analysis of those needs and discuss how enduser-programmable toolkits could better engage with both those household members who design new automated functions and those who merely 'use' them.
\end{abstract}

\section{CCS CONCEPTS}

- Human-centered computing $\rightarrow$ Empirical studies in ubiquitous and mobile computing.

\section{KEYWORDS}

end-user programming, internet of things, smart homes, in-the-wild study, trigger-action programming, appropriation

ACM Reference Format:

Antti Salovaara, Andrea Bellucci, Andrea Vianello, and Giulio Jacucci. 2021. Programmable Smart Home Toolkits Should Better Address Households' Social Needs. In CHI Conference on Human Factors in Computing Systems (CHI '21), May 8-13, 2021, Yokohama, Japan. ACM, New York, NY, USA, 14 pages. https://doi.org/10.1145/3411764.3445770

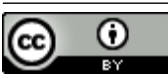

This work is licensed under a Creative Commons Attribution International 4.0 License.

CHI '21, May 8-13, 2021, Yokohama, Japan

(c) 2021 Copyright held by the owner/author(s).

ACM ISBN 978-1-4503-8096-6/21/05.

https://doi.org/10.1145/3411764.3445770

\author{
Andrea Bellucci \\ Universidad Carlos III de Madrid \\ Spain \\ abellucc@inf.uc3m.es
}

\section{INTRODUCTION}

The proliferation of several developments - Internet of Things (IoT) advances, the do-it-yourself (DIY) and maker movement, awakening to the need for a low-energy lifestyle, and general digitalisation of day-to-day life - have made smart homes a focus of considerable commercial and academic interest [14, 33, 38, 45]. Home appliances can now be controlled via voice-based personal assistants [1], room temperatures can be adapted to users' preferences automatically [31], and Arduino [2] and Raspberry Pi [23] systems offer makerminded people open-ended platforms for their own automation designs, with connectability to many IoT devices either directly or via IFTTT [36] or other interfaces [6, 18].

All the enthusiasm notwithstanding, a great challenge remains: modern homes have been honed, over the centuries, to render lives as convenient and easy as possible [21], yet the scenarios of 'smart homes' are aimed at evoking desire for even higher levels of convenience, aesthetics, and 'pleasance' [59]. Though needs in domestic settings evolve over time [53] and new ones do emerge, people find it rather hard to pinpoint elements that truly demand technological mediation. Apart from specific needs for increased security against thieves, [52], energy savings [32, 58], and aids for assisted living [29], it is entirely possible that households might not perceive sufficient utility in the smart-home technologies envisioned.

We addressed this challenge connected with the real-world necessity of smart-home technologies, asking: What smart-home automation do technically competent families actually ideate, implement, use, and - most importantly - need? To identify diverse uses for these technologies - potentially useful ones but also novel, social, and fun applications [26] - we deployed a smart-home toolkit of our own design in four carefully selected family homes, actively facilitated their appropriation over the following six weeks, and evaluated the results. We found that the concerns outlined above are largely warranted: the households did not easily find uses for our toolkit, even when we actively assisted. However, we also identified forms of successful social uses that have not seen widespread discussion in the literature. We summarise our findings thus:

- Smart-home toolkits can be difficult to appropriate even for users who possess the motivation and competence for ready appropriation of this technology.

- There are unaddressed social patterns, however, that may afford successful appropriation. 


\section{RELATED RESEARCH}

In our definition, smart-home toolkits are consumer technologies comprising several interconnectable devices that can be used to measure and monitor situations and events in the home, and to take action accordingly [38]. The toolkit might comprise, for example, a Wi-Fi-equipped accelerometer that transmits its data wirelessly and a receiving base unit that can be programmed to switch lights on and off on the basis of accelerometer data. Via such a sensor and actuator set-up, the lights can be turned on automatically whenever a door is opened. We call these assemblages of technologies 'toolkits', because their composition is open-ended; they form a network of heterogeneous interoperable devices and are programmable by users. Accordingly, they are designed not to serve predefined needs but to provide users with tools to realise smart-home behaviours of their own liking $[5,57]$.

\subsection{How Smart-Home Toolkits Support Appropriation by Users}

Smart-home toolkits can be appropriated - taken up, adapted, and integrated into existing practices $[38,66]$ - in many ways, to serve various household and individual-level needs. This brings with it the challenge of providing tools that are amenable to end users' programming and configuring of the toolkits, since not all desires can be addressed by visualisations [34] or demonstrations [24] alone. A particularly pertinent problem is that end users of domestic technologies might not all be expert programmers $[3,64]$. Therefore, a great deal of interest has been devoted to creating methods and interfaces that support users in configuring smart behaviours by themselves via simplified programming paradigms [20, 42].

Recently, smart-home toolkit design has started to explore the opportunities provided by trigger-action programming [62], a paradigm where rules can be defined in the form of 'if something happens' (the trigger), 'then do something' (the action). This simple syntax enables programming for a wide range of user activities and needs [62], but it is not flawless. When triggers and actions are mapped to a larger ecosystem, including multiple devices, sensors, and Web-based channels, several triggers and actions must operate as a joint composition, together. Extending the expressiveness of the syntax with additional constructs (such as and/or logic, loops, and state variables) complicates rules' understandability [30, 35]. For instance, rules may be ambiguous, or competing outputs might be involved [35]. Moreover, however simple it may appear, triggeraction programming is not immediately understandable to all nonexperts $[11,20,30]$. To tackle this issue, developers are developing various interactive programming interfaces $[6,15,20]$.

User engagement with smart-home toolkits is another issue, since programming-like activities are far from thrilling to many users [5,22]. Lately, solutions that gamify end-user programming for the smart home have drawn interest [20, 22, 43]. These are grounded in self-determination theory (SDT), which suggests that humans have three fundamental needs [51]: for autonomy (opportunities to make one's own choices), relatedness (creation of social bonds between oneself and others), and competence (striving to master skills that one finds important). To encourage users further toward behaviours that match their needs, toolkits can employ a bottom-up gamification approach [43]. This design tactic turns users into game designers whose creations support the needs of their communities, rather than consumers who are subjected to strive towards goals determined by designers. While we did not seek to contribute to bottom-up gamification, the study borrowed from it in our method of facilitation for users during the field trial.

\subsection{What Smart Home Toolkits Are Used For}

Smart-home toolkits' open-endedness makes it important to find ways to support for serendipitous discoveries of novel uses [5]. By analysing the purposes for which smart-home toolkits are actually used, we can support this development. Ur et al.'s analysis of automated services created with IFTTT $[62,63]$ indicates that date/time and location were the most frequently used triggers at the time of writing, while the most desired action was to receive notification (e.g., via email). The authors found, in all, 21 distinct trigger and 46 distinct action channels for domestic end-user programming [62]. This attests to the heterogeneity of uses that smart-home toolkits can afford. Because of their dataset's size and nature, however, Ur et al. could not analyse the goals behind the numerous rules.

Mennicken and Huang's [45] survey reveals that most studies of toolkits' uses have been based on ideation workshops. For example, a workshop-based project by Brich et al. [12] identified end-user programming uses that afford convenient living (e.g., automating devices for morning and returning-home routines), energy savings, and security, while a more detail-level study by Bellucci et al. [6] pinpointed 11 possible use areas: comfort, safety, parenting, resource conservation, health and fitness, home maintenance, reminders about objects, entertainment, security, cooking, and education. Other ideation reports present uses related to emotional and personal value [8] and to intimacy [7]. However, what people articulate in workshop settings may not culminate in actual use.

To our surprise, not much has been published on in-the-wild studies of smart-home technology, as became apparent through a systematic literature review [47]; full-text searches of the ACM, Elsevier, Springer, and IEEE libraries; and reference to the Google Scholar database for completeness. We employed the following query string: $\mathrm{Q}=$ ('smart home' or 'home automation') AND ('in the wild' OR 'field study') AND 'end user' AND 'program*'. Our searches included only research papers from peer-reviewed journals, magazines, or conferences, and we excluded pieces that 1) did not discuss results from empirical research (e.g., [48, 49]), 2) reported results from lab or elicitation studies with non-functional probes or discussed in-the-wild studies only as proposed future work (e.g., $[12,16])$, and/or 3) focused on usability or programming techniques rather than end users' appropriation (e.g., [10, 22, 46]).

Our final corpus consisted of 14 papers, summarised in Table 1. The overall finding (see the table's last column) is that support for convenience via small automation instances attracts considerable interest, possibly motivated by a desire for 'peace of mind'. Also worthy of note are the finding by Funk et al. that trigger-action programming responds insufficiently to more fully articulated needs (e.g., social ones) [25] and Denefleh et al.'s exploration of opportunities for gamification in this regard [19]. However, none of the reports presented thorough classification of the automated services created and used by participants: the authors' main focus was always on other matters. In addition, the uses were described mostly 
Table 1: Studies on in-the-wild smart home appropriation

\begin{tabular}{|c|c|c|c|c|}
\hline Authors & $\begin{array}{l}\text { User group }(N \text { of } \\
\text { households) }\end{array}$ & Method & System type & $\begin{array}{l}\text { User-created } \\
\text { reported upon }\end{array}$ \\
\hline $\begin{array}{l}\text { Denefleh et al. } \\
2019 \text { [19] }\end{array}$ & $\begin{array}{l}\text { Students living in a } \\
\text { shared flat (1) }\end{array}$ & 19 days' deployment & $\begin{array}{l}\text { Sensors whose data streams } \\
\text { and notifications are shown } \\
\text { in a display and instant } \\
\text { messenger }\end{array}$ & $\begin{array}{l}\text { Creating positive connections among resi- } \\
\text { dents, self-monitoring, control over others, } \\
\text { and rewards and penalties }\end{array}$ \\
\hline $\begin{array}{l}\text { Tewell et al. } 2019 \\
{[61]}\end{array}$ & $\begin{array}{l}\text { Tech enthusiasts } \\
\text { testing sensors for } \\
\text { assisted living (4) }\end{array}$ & One-day field trial & $\begin{array}{l}\text { Off-the-shelf monitoring } \\
\text { sensors without end-user } \\
\text { programmability }\end{array}$ & $\begin{array}{l}\text { No appropriation: focus on predefined uses for } \\
\text { people with dementia or Parkinson's disease }\end{array}$ \\
\hline $\begin{array}{l}\text { Geeng and } \\
\text { Roesner } 2019 \text { [28] }\end{array}$ & $\begin{array}{l}\text { Residents interested } \\
\text { in smart homes (14) }\end{array}$ & $\begin{array}{l}\text { Three-week } \\
\text { deployment }\end{array}$ & Commercial devices & $\begin{array}{l}\text { Convenience automations* for support in day- } \\
\text { to-day life }\end{array}$ \\
\hline $\begin{array}{l}\text { Funk et al. } 2018 \\
{[25]}\end{array}$ & One of the authors (1) & $\begin{array}{l}\text { Three-year } \\
\text { deployment in an } \\
\text { author's home }\end{array}$ & $\begin{array}{l}\text { Appr. } 100 \text { devices and } \\
\text { sensors connected using } \\
\text { SmartThings, IFTTT and } \\
\text { Stringify }\end{array}$ & $\begin{array}{l}21 \text { automated functions for automatic control } \\
\text { and } 16 \text { for automatic notification }\end{array}$ \\
\hline $\begin{array}{l}\text { Jakobi et al. } 2018 \\
\text { [39] }\end{array}$ & $\begin{array}{l}\text { Residents with } \\
\text { existing systems (12) }\end{array}$ & 26-month living lab & $\begin{array}{l}\text { An end-user-programmable } \\
\text { commercial system }\end{array}$ & $\begin{array}{l}\text { Convenience automations* for support in day- } \\
\text { to-day life. }\end{array}$ \\
\hline $\begin{array}{l}\text { Jensen et al. } 2018 \\
{[40]}\end{array}$ & $\begin{array}{l}\text { Residents with } \\
\text { existing systems (23) }\end{array}$ & $\begin{array}{l}\text { Home tours and } \\
\text { interviews }\end{array}$ & $\begin{array}{l}\text { Various systems with } \\
\text { limited end-user } \\
\text { programmability }\end{array}$ & $\begin{array}{l}\text { Helping, optimising and offering 'hedonistic' } \\
\text { aesthetic experiences. }\end{array}$ \\
\hline $\begin{array}{l}\text { Jakobi et al. } 2017 \\
\text { [38] }\end{array}$ & $\begin{array}{l}\text { Heterogeneous } \\
\text { household } \\
\text { composition (14) }\end{array}$ & 18-month living lab & $\begin{array}{l}\text { Freedom to choose } \\
\text { technologies from the } \\
\text { researcher-provided list }\end{array}$ & $\begin{array}{l}\text { Convenience automation* supporting day-to- } \\
\text { day life, incl. monitoring of daily activities and } \\
\text { time-series analysis }\end{array}$ \\
\hline $\begin{array}{l}\text { Coutaz and } \\
\text { Crowley } 2016 \\
{[17]}\end{array}$ & $\begin{array}{l}\text { Research team } \\
\text { members (5) and } \\
\text { heterogeneous } \\
\text { household } \\
\text { composition (5) }\end{array}$ & $\begin{array}{l}\text { Installation in authors' } \\
\text { homes ( } 4 \text { mo.), other } \\
\text { homes ( } 3 \text { weeks), and } \\
\text { the two authors' home } \\
(12+\text { mo.) }\end{array}$ & $\begin{array}{l}\text { Block-based scripting able } \\
\text { to control smart plugs, } \\
\text { buttons, etc. }\end{array}$ & $\begin{array}{l}\text { Convenience automation* to support in day- } \\
\text { to-day life, incl. support for peace of mind, } \\
\text { comfort and leisure, social gatherings, secu- } \\
\text { rity, hygiene, and making energy consumption } \\
\text { visible }\end{array}$ \\
\hline $\begin{array}{l}\text { Woo and Lim } \\
2015 \text { [64] }\end{array}$ & $\begin{array}{l}\text { Families with at least } \\
\text { one member } \\
\text { interested in DIY (8) }\end{array}$ & Three-week f & $\begin{array}{l}\text { Trigger-action toolkit and } \\
\text { commercial devices }\end{array}$ & $\begin{array}{l}167 \text { rules but no analysis of their content (ex- } \\
\text { amples of automated lighting and movement } \\
\text { detection) }\end{array}$ \\
\hline $\begin{array}{l}\text { Mennicken et al. } \\
2014 \text { [45], } \\
\text { Mennicken and } \\
\text { Huang } 2012[44]\end{array}$ & $\begin{array}{l}\text { People dwelling in } \\
\text { smart homes (7) and } \\
\text { residents with a } \\
\text { non-technical } \\
\text { background (5) }\end{array}$ & $\begin{array}{l}\text { Interviews and mixed } \\
\text { methods }\end{array}$ & $\begin{array}{l}\text { Several systems with limited } \\
\text { end-user programmability }\end{array}$ & $\begin{array}{l}\text { Convenience automation* to support day-to- } \\
\text { day living }\end{array}$ \\
\hline $\begin{array}{l}\text { Takayama et al. } \\
2012[60]\end{array}$ & $\begin{array}{l}\text { Early adopters and } \\
\text { tech enthusiasts }(10)\end{array}$ & Interviews & Commercial devices & $\begin{array}{l}\text { Energy, security, lighting, irrigation, climate } \\
\text { control, entertainment and peace of mind }\end{array}$ \\
\hline $\begin{array}{l}\text { Brush et al. } 2011 \\
{[13]}\end{array}$ & $\begin{array}{l}\text { People living in smart } \\
\text { homes (14) }\end{array}$ & Interviews & $\begin{array}{l}\text { Several systems with limited } \\
\text { end-user programmability }\end{array}$ & $\begin{array}{l}\text { Convenience automation* that supports day- } \\
\text { to-day living, peace of mind, and control. }\end{array}$ \\
\hline $\begin{array}{l}\text { Woodruff et al. } \\
2007 \text { [65] }\end{array}$ & $\begin{array}{l}\text { Orthodox Jewish } \\
\text { families }(20)\end{array}$ & $\begin{array}{l}\text { Home visits and } \\
\text { interviews }\end{array}$ & Various commercial systems & $\begin{array}{l}\text { Timers used to control electrical appliances on } \\
\text { the Sabbath. }\end{array}$ \\
\hline
\end{tabular}

* Automation mechanisms designed to automate small daily tasks, thereby saving user effort.

in anecdotal remarks. Specifically, we found a clear gap in that no paper analysed which uses were visible in real-world practice vs. which may have been useful in principle but had been abandoned.
We concluded that research is still lacking detailed analysis of what users do with end-user-programmable smart-home toolkits: what automation they actually create and use. Our study addressed this gap. 


\section{SMART HOME TOOLKIT}

To conduct the field studies in the domestic environment, we designed a smart-home IoT toolkit, proceeding from the findings from the above-mentioned feature-elicitation studies $[4-6,12]$ and pursuing open-endedness in our design. We equipped the toolkit with a wide range of typical trigger-action channels to cater for ordinary automated services that could simplify living, notify or remind of important events, and serve both utilitarian and hedonic needs. Additionally, we integrated game elements into the toolkit design (counters, rewards, etc.) in the spirit of bottom-up gamification [43]. The game functionality was an optional appropriation opportunity offered in efforts to spur the creation of novel social and playful appropriation [26].

\subsection{Triggers and Actions}

We wanted to optimise for easy uptake and avoid requiring advanced technical competence of those who would be participating. This ruled out a system based on the popular IFTTT ecosystem. We deemed operating it on one's own to require too much technical skill and thereby encourage a situation in which each household would likely have only one user. Also, we wanted to experiment with certain extensions to trigger-action programming not supported by IFTTT. We describe our extension in Subsection 3.2.

In our implementation of the toolkit, we built on a wide selection of robust commercial IoT technologies that users could appropriate in their creation and use of automated services. These features and their connection architecture are presented in Figure 1. The technologies interfacing with our base unit could be used as triggers (i.e., inputs), actions (i.e., outputs), or both.

The trigger-only technologies were 1) Texas Instruments SensorTags [37] that can measure various ambient parameters (e.g., light levels and temperature); 2) near-field communication (NFC) tags readable by a chip reader embedded in our toolkit's base unit; and 3) a proprietary electricity meter, which our partner company installed in the fuse board of each household. Using voltage and current fingerprinting, it could identify the use of energy-hungry electric appliances, such as kitchen equipment, hair-dryers, and vacuum-cleaners. The action-only technologies featured 1) loudspeakers that could play both pre-selected and user-uploaded audio samples and 2) notification by email. Finally, there were several technologies with both trigger and action functionality: 1) Fibaro Wall Plugs [55], with wireless readability and control; 2) Philips Hue lamps [50]; 3) technologies for calendar- and time-based events (e.g., alarm clocks); and 4) instance/event and elapsed-time counters.

The triggers and actions were controlled via a base station implemented with a Raspberry Pi. We handled the connections to the individual IoT technologies by using a Node.js back end and the Bluetooth low energy (BLE), Wi-Fi, and Zigbee wireless communication protocols. The base station was in constant contact with our server, to which it delivered interaction logs and with which it managed the server-side inputs and such actions as processing email and calendar events. This server also provided a Web-based interface that families' mobile devices could access to create and edit trigger-action rules and check the status of their automated services. In addition, the server received data from the dedicated server of the electricity meter.

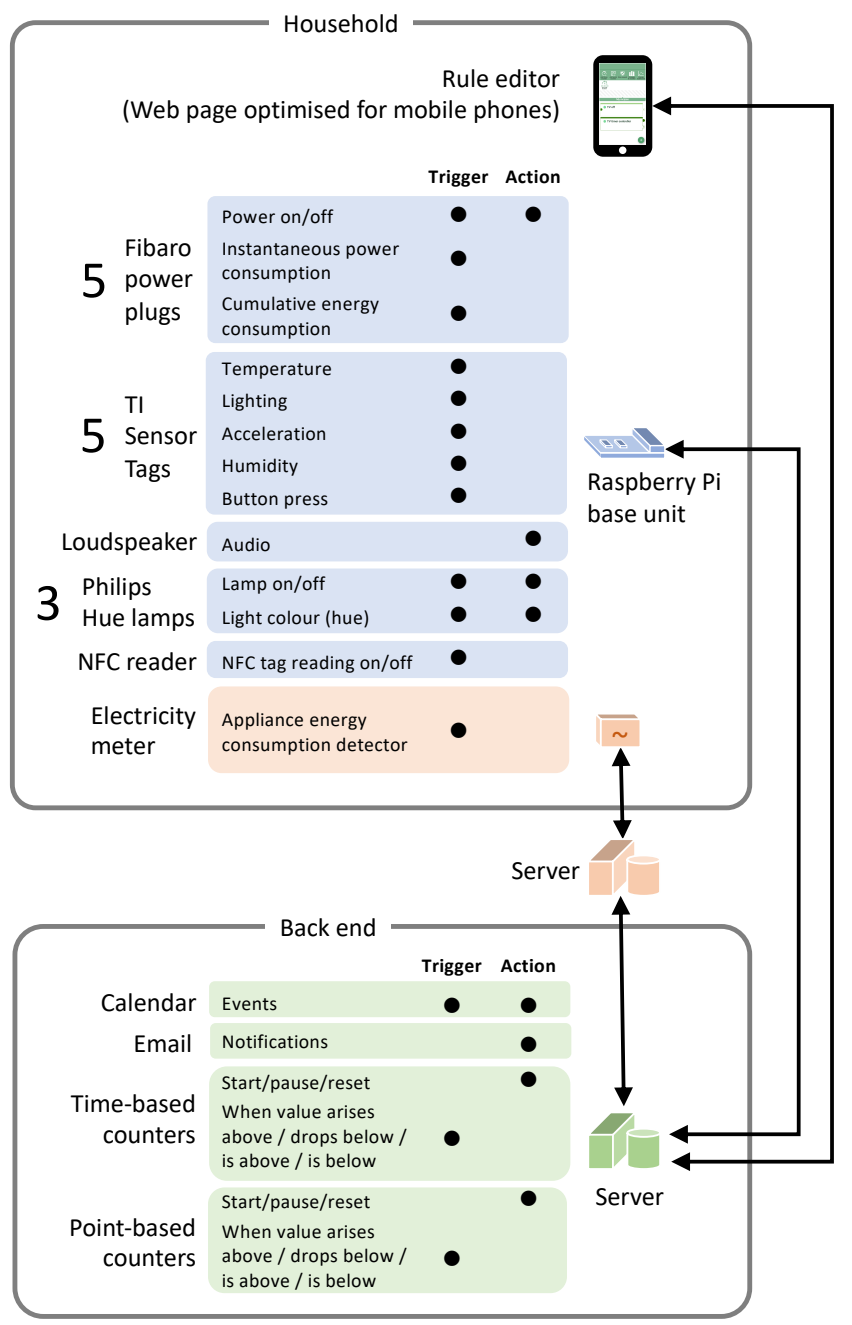

Figure 1: Our smart home toolkit's communication architecture and the triggers and actions available for users.

\subsection{Extended Trigger-Action Rule Editor}

Our rule editor was designed for use on a mobile phone. We opted for trigger-action rules as the basis for the editor. However, since process-oriented flow-based programming is computationally more expressive than rules only, thereby catering better to specific user needs [12], we extended the trigger-action model in two ways.

Firstly, we supported chaining several rules to create more complex automation [12]. Figure 2 presents the actions for creating chained automation by linking several rules. Rules are shown graphically as pieces in a simple jigsaw puzzle, with a tab on its right-hand (output) side displaying a plus sign if said rule's output could act as input for another rule. Tapping the tab takes the user directly to a new editor view, for creation of rules, where a new rule is pre-populated with an input from the output in question. Once the rule is completed, chaining is denoted by displaying the output from the source rule and the input to the newly established rule in the same colour. This helps the user visualise the process involved. 

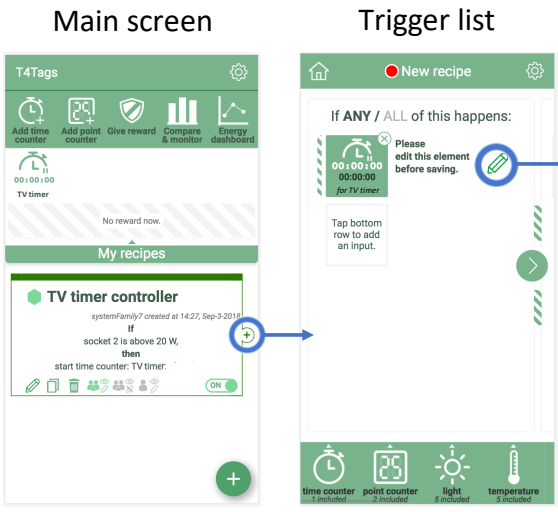

Starting point: The user has already created a time counter called 'TV timer' and a rule ('TV timer controller') that starts the time counter when powe socket no. 2 reports that the power is on.

The user taps $\subsetneq$ to create a chained rule.
The rule editor's trigger list opens, pre-populated with 'TV timer' as its input. The user taps the pen symbol to define the conditions for when their new chained rule should be triggered.

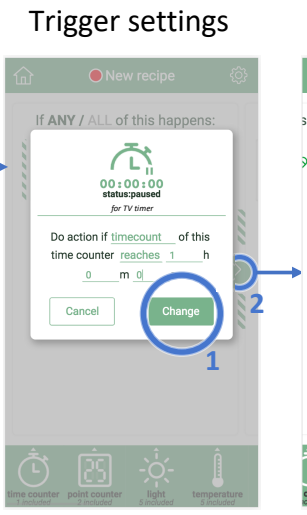

A pop-up dialog for trigger settings opens.

User sets this new rule to be triggered when the 'TV timer' reaches one hour. They 1) confirm the settings by tapping 'Change' and, when the pop-up closes, 2) moves to defining the rule's action settings by tapping the arrow symbol, ?

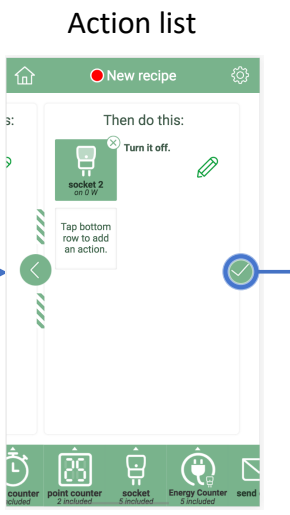

The rule editor's action portion opens.

(Not shown: The user taps a socket icon in the bottom row and picks 'socket 2' from the list that springs up. A pop-up similar to the one on the left opens. The user specifies that the socket's action will be 'Turn it off', after which they close the pop-up.)

Having now specified the action, the user taps the icon.

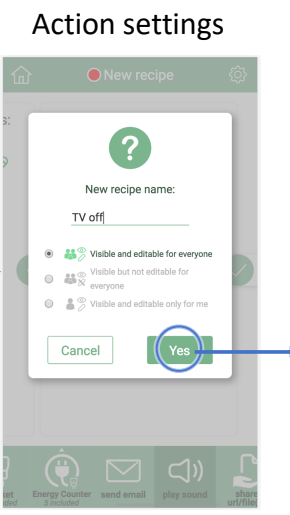

A pop-up dialog asks the user to provide a name for the new rule.

The user enters the new name and taps 'Yes'.

(1)

the

Main screen

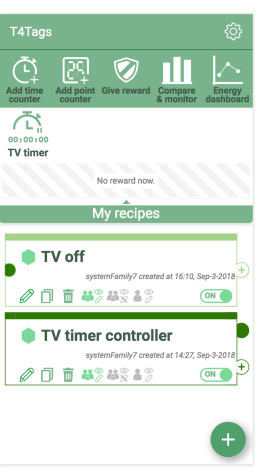

The rule list, ordered by recency, now shows the new rule. The chaining from 'TV timer controller' to 'TV off' is indicated by the jigsaw puzzle icon (D) of the same colour. More chains and entirely new rules can be created by tapping the $\subsetneq$ and $\odot$ icons.

Figure 2: Creation of a chained rule in our smart-home toolkit's rule editor.

For a second technique responding to the need for greater expressiveness [6,35], we introduced event- or instance-based pointaccumulation counters and time-accumulation counters. The former enabled tracking the number of times something has happened or instances of an event and, on that basis, awarding points to an individual user or the entire family. This could be used in monitoring, for instance, how many times a lamp gets switched on or the fridge door is opened in the course of the day. Quantities of points can serve as triggers, allowing for the creation of point-based competitions among participants. Time-accumulation counters, on the other hand, let users define rules based on the passage of time (features for pausing, restarting, and reseting the counter are available). Actions and further rules alike can be triggered on the basis of the timer's value. For example, in Figure 2, 'TV timer controller' starts a timer every time the power point connected to the television set is turned on. This rule is chained to a 'TV off' rule to control the total time for which children may watch television on any given day; for instance, the second rule could be set to switch off the power to this outlet when the timer reaches two hours.

In addition, we provided live contextual information [6] and feedback [15] to help users ascertain, during rule creation, that their rules were behaving as intended. All input and output values were updated in real time in the mobile phone's editor. For example, the light level shown in the interface would immediately respond to the user placing a hand over the associated SensorTag. Speaking to multiple needs and ways of thinking, the measurements are presented both iconically (e.g., via a bright vs. dim lamp icon) and as precise figures (e.g., 100 lux).

\section{METHODS}

We strove for study conditions favourable for successful appropriation, by considering family compositions, technical skills, life values, etc. Success in appropriation with these participants should generate findings that contribute to developing smart-home toolkits that reflect new design opportunities. On the other hand, should appropriation fail even in circumstances so conducive to it, this would corroborate our doubts about toolkits' general appropriability. We could then consider how research in this field might be fruitfully reoriented. Our approach to these doubts was inspired in part by Gaver et al.'s studies [27] demonstrating how, when a well-prepared technology fails in real-world conditions, the failure may offer even more valuable lessons than a positive reception.

\subsection{Participants}

We carried out pilot studies with two families. The purpose in this was to learn about the robustness of the toolkit, any usability problems, and appropriation that might occur in the absence of facilitation of active use. Each pilot study lasted 2.5 months and included an installation visit, a mid-study interview, and a final interview. For the pilot phase, we deliberately recruited households with parents interested in technology, programming, and DIY activities. Furthermore, there was evidence of motivation: the parents described themselves as interested in reducing their energy consumption. Nonetheless, our main finding was that, while the toolkit proved robust enough for stand-alone use, both sets of parents and their children found it difficult to devise uses for our toolkit. 
Table 2: Informant demographics and background

\begin{tabular}{|c|c|c|c|}
\hline Family & $\begin{array}{l}\text { Genders } \\
\text { and ages }\end{array}$ & $\begin{array}{l}\text { Educational } \\
\text { background }^{b}\end{array}$ & $\begin{array}{l}\text { Programming } \\
\text { experience }^{c}\end{array}$ \\
\hline $\begin{array}{l}\text { F1 } \\
\text { (Finland }\end{array}$ & $\begin{array}{l}\text { Male, } 54 \\
\text { Female, } 50 \\
\text { Male, } 17 \\
\text { Male, } 15\end{array}$ & $\begin{array}{l}* * * * * \\
* * * * * \\
* * * \\
* *\end{array}$ & $\begin{array}{l}* * * \\
* * * \\
* *\end{array}$ \\
\hline $\begin{array}{l}\mathrm{F} 2 \\
\text { (Finland }\end{array}$ & $\begin{array}{l}\text { Female, } 51 \\
\text { Male, } 16 \\
\text { Male, }^{a}\end{array}$ & $\begin{array}{l}\text { **** Civic engineering } \\
* * \text { Business IT } \\
-(\text { unknown })\end{array}$ & $\begin{array}{l}* * \\
* * \\
-(\text { unknown })\end{array}$ \\
\hline $\begin{array}{l}\text { F3 } \\
\text { (Finland }\end{array}$ & $\begin{array}{l}\text { Male, } 42 \\
\text { Female, } 39 \\
\text { Female, } 9^{d} \\
\text { Female, } 7^{d}\end{array}$ & $\begin{array}{l}* * * * * \text { Computer science } \\
* * * * * \text { Social sciences } \\
* \\
*\end{array}$ & $\begin{array}{l}* * * \\
* * \\
*\end{array}$ \\
\hline $\begin{array}{l}\text { F4 } \\
\text { (Spain) }\end{array}$ & $\begin{array}{l}\text { Male, } 45 \\
\text { Female, } 42 \\
\text { Male, } 11 \\
\text { Male, } 10 \\
\text { Female, } 6^{d}\end{array}$ & $\begin{array}{l}{ }^{* * * * *} \text { Electrical eng } \\
* \\
* \\
*\end{array}$ & $\begin{array}{l}* * * \\
* * * \\
* * \\
* * \\
*\end{array}$ \\
\hline
\end{tabular}

$a \overline{\text { A tenant occupying a room in F2's household who joined at a later stage }}$ and did not fill in the questionnaire.

$b{ }^{*}=$ Comprehensive-school level at most, ${ }^{* *}=$ In vocational high school, 'Vocational high school', given the order here? -als ${ }^{* * *}=$ Secondary school, ${ }^{* * * *}=$ Univ. studies, and ${ }^{* * * * *}=$ Univ. degree.

$c *$ No experience, ${ }^{* *}=$ Some experience, and ${ }^{* * *}=$ A lot of experience.

${ }^{d}$ Did not participate in the workshops.

In the full-scale studies, carried out with four families, we attempted to guarantee that our methods facilitate families' appropriation of the toolkit. Accordingly, we recruited households with a very specific profile. Firstly, we focused on families with children of different ages, so as to investigate a wider range of social dynamics and playful uses for children's upbringing. In addition, we wanted to make sure that the users could readily understand the trigger-action logic, so we selected families in which at least one adult possessed computer-science or other technical knowledge. Thirdly, we gave preference to families interested in saving energy and following a more ecologically friendly way of life, because some features of our toolkit were related to energy consumption. To this end, we verified that at least some of the participants, living in single-family homes, were paying all of the dwelling's energy costs. Table 2 summarises the descriptive data from a background questionnaire that gathered basic demographic details and information about participants' programming experience.

We rewarded each family for their time and effort with 200- or 300-euro compensation, depending on the size of the family.

\subsection{Facilitation Workshops}

We studied ideation, implementation, and use experience related to smart-home toolkits by meeting with each family four times, making an installation visit, and holding three in-situ workshops with each family. Every visit lasted approximately two hours. We worked with each family in a sequence, with minimal overlap, which allowed us to improve our methods.

The realities of the households made all the visits slightly different from each other. All members of F1, F2, and F4 participated in all workshops held in the home, while F3's children were younger so neither took part in the workshops nor created their own automated services. Family 2 had an Italian tenant who wanted to participate in the study but whose room was on a different floor, too far away for a wireless connection with the base station. While he was active in the workshops, his first-hand experience with the toolkit remained limited. We video-recorded the visits, and we transcribed those portions of the resulting 19.3 hours of material that contained discussion. There were long stretches of silent work that did not require detailed transcription but produced other documentation.

To discover such uses as could have a lasting positive effect on the family, we facilitated ideation and implementation via methods that tie in with family members' innate needs. In line with this goal, we adopted SDT [54] for guidance with the facilitation methods.

4.2.1 Visit 1: Installation and Orientation. The first visit to each family involved two main tasks: installation of the toolkit and establishing mutual familiarity. Simultaneously with installation, one researcher interacted with the participants, obtaining informed consent and participation permission for the junior family members from their guardians, explaining the purpose of the study, and administering the background questionnaire for each participant.

While we did not gather specific information from F1 during this visit, we augmented our data collection after this. For F2, F3, and F4, we took a more structured approach, utilising the following list of life areas in which automation could play a role: comfort, safety, parenting, monitoring and control, use of (energy) resources, health, prevention of human error, entertainment and fun, security, tools, and the distribution of work/chores within the family. For each area, we articulated 1-3 sub-areas, for 18 distinct discussion topics in all. Each was printed on a separate sheet of A5 paper. We discussed their importance one by one with the entire family, gathering their notes on the various pieces of paper. After discussion of a topic, every participant rated the associated needs with 1-5 stars. Figure 3 shows two sample pieces of paper from the discussion.

We concluded the visit with a demonstration of the toolkit and left simple homework for the family to complete before our next visit: 'create a rule that uses the NFC reader'. The family could then start using the fully operational system as they saw fit.

4.2.2 Visit 2: The Ideation Workshop. Our second visit took place at least one week later. We started by asking the families to show us any automated services they had created. We then began the in-situ ideation workshop, dividing the family into pairs, with one researcher facilitating each pair's ideation. The goal for the workshop was to help the family members come up with uses for the smart-home toolkit in their home and get inspired by its potential.

To this end, we took the family's output from visit 1 , on the above-mentioned 18 discussion topics, as a starting point for deeper idea-oriented discussion. Along with the families' hand-written notes and ratings, the papers now included researcher-generated discussion-starters in addition (see Figure 3), created on the basis of our impressions from the first visit. These were not ideas for 


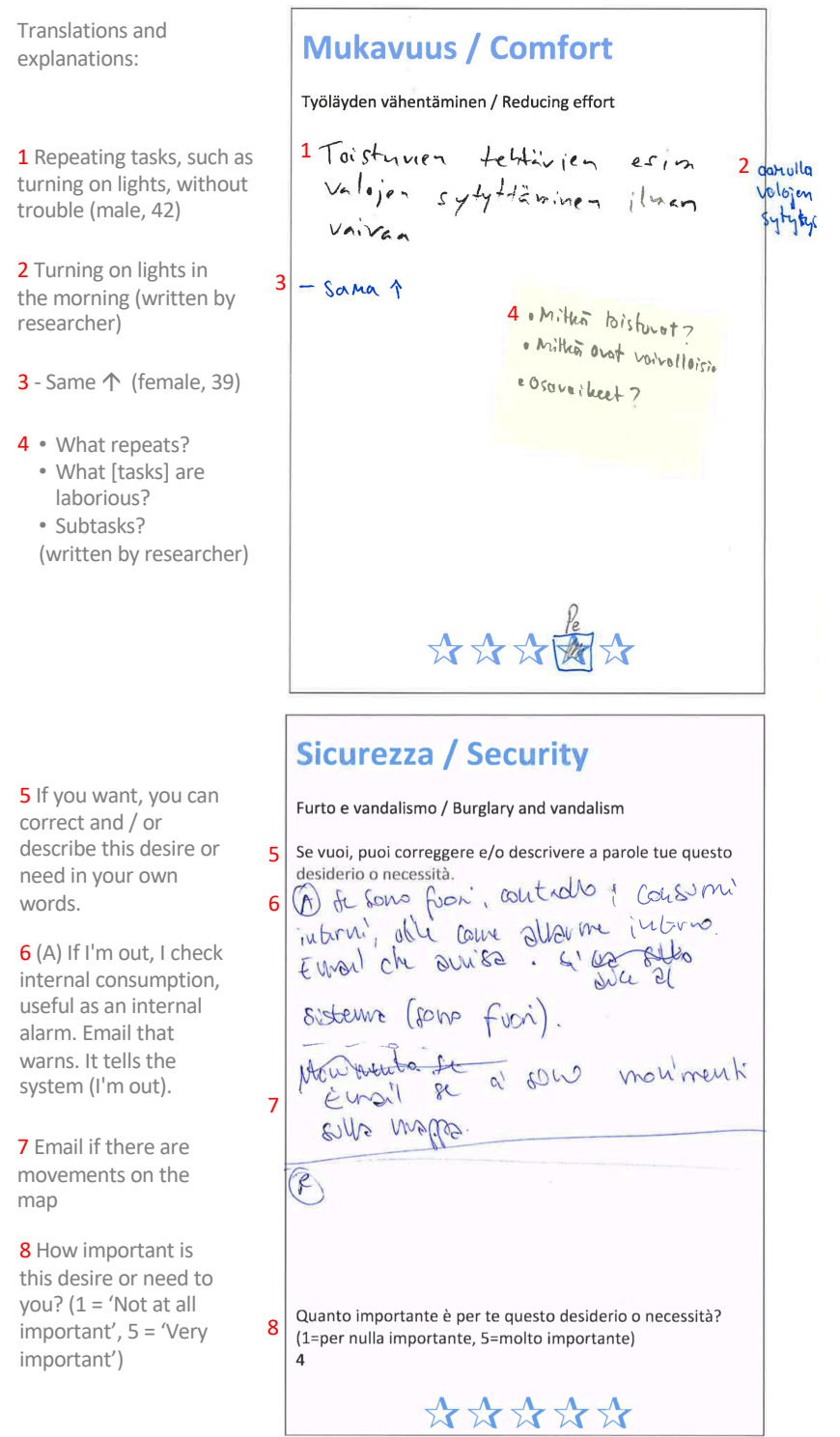

Figure 3: Ideation content from visits 1 and 2, produced on A5-sized discussion cards by families 3 and 4 . Notes 2 and 4 were written by the researcher who acted as a scribe in the ideation process and prepared discussion-starters for visit 2 .

particular rules or automation entities but notes elaborating on needs that we thought we had heard the family express.

Before leaving, we again gave the family members homework. With each workshop participant, we chose one idea and asked them to implement it before our next visit. Also, we encouraged all family members to continue using the toolkit in their own ways.

4.2.3 Visit 3: The Design and Implementation Workshop. The third meeting took place after another break of at least one week. This time the objective was to turn ideas into rules and automated services. We started by presenting the ideas that the family had generated during the previous visit. We had pre-selected 1-2 items
Table 3: Automation devised vs. actually implemented

\begin{tabular}{llll}
$\begin{array}{c}\text { Family No. of active No. of ideas No. of automated func- } \\
\text { participants }\end{array}$ & from visit $\mathbf{1}$ & tions deployed \& used \\
\hline F1 & 4 & 45 & 4 \\
F2 & 3 & $15\left(+31^{a}\right)$ & $0\left(+4^{a}\right)$ \\
F3 & 4 & 10 & 4 \\
F4 & 4 & 11 & 6 \\
\hline
\end{tabular}

$\bar{a}$ A tenant who joined at a later stage and did not fill in the questionnaire.

that were implementable with our toolkit and that were likely to be among the most interesting, in light of our analysis of earlier visits.

While some ideas could be readily translated into automation, ideas stemming from relatedness and competence needs were typically more complicated; e.g., some were related to the distribution of work in the household or motivating family members to do something they found unpleasant. In an attempt to turn those ideas into automated services, we asked the family members to regard them as games. We described several ways in which our toolkit could support game design, and stated that games are often designed around challenges and goals. We mentioned setting up such things as target levels for point-accumulation, competitions involving comparisons of family members' point counts, and rewards for desirable actions.

We then let the families design rules and chain them if necessary, to create more complex automation. In most families, the two hours that we promised to stay elapsed quickly, and we had to leave before all of the services were finished and tested in operation. We asked the families to continue working on them so that we could interview them when meeting for the fourth and last time.

4.2.4 Visit 4: The User-Experience Workshop. We left at least two weeks between visit 3 and our final meeting, to give the families more time to finish creating the services that they had started designing and to accumulate experience of using them, along with any further ones they had created.

Before the visit, we captured screenshots of all the rules as presented in the editor, analysed how they were chained together, clustered them, and printed them out on large (A3) sheets of paper. In the meeting with the family members, we asked the principal creator of each automation service (possibly comprising several individual rules) to describe the automation. We expressed particular interest in hearing stories about the uses of the automation and about related experiences. We concluded the discussion of each service by asking all participants to rate it (on a scale of 1-5) with respect to how well it meets the needs in each of the three SDT categories and to explain the reason for the rating given.

The workshop concluded with general debriefing on matters related to the study. We asked the participants to tell us anything else they found it relevant to add. Then, we dismantled and packed up the toolkit, agreed on the method for providing financial compensation, thanked the family warmly, and left.

\section{FINDINGS}

Before we delve into our findings on smart home toolkits' appropriation, we note the differences between families. While F1, F3, 
Table 4: Results of the ideation workshop

\begin{tabular}{|c|c|c|}
\hline Class (count) & Description & Example (family) \\
\hline \multicolumn{3}{|l|}{ Utilitarian automation: } \\
\hline Helpers (26) & Elimination of repetitive tasks & 'Turn on ambient kitchen lights in the morning' (F3) \\
\hline Reminders (10) & Notifications about important things & 'Reminder to record a TV show' (F2) \\
\hline \multicolumn{3}{|l|}{ Motivational automation: } \\
\hline Behaviour change (15) & Aiding with self-initiated positive change & $\begin{array}{l}\text { 'The family co-operate on a shared mission to reduce consump- } \\
\text { tion' (F4) }\end{array}$ \\
\hline \multicolumn{3}{|l|}{ Social automation: } \\
\hline Resource-sharing (12) & Helping families agree about shared resources & 'Who takes the dog out' (F2) \\
\hline Child-rearing (9) & $\begin{array}{l}\text { Educating children to take responsibility or learn } \\
\text { important skills }\end{array}$ & $\begin{array}{l}\text { 'A reward if the kids go to bed early or they do their homework' } \\
\text { (F4) }\end{array}$ \\
\hline \multicolumn{3}{|l|}{ Other automation: } \\
\hline Security and safety (14) & Hazard-prevention, warnings, and monitoring & 'Email us if the door opens while we're on holiday' (F4) \\
\hline Information (6) & $\begin{array}{l}\text { Measuring things without an immediate goal of } \\
\text { using the information }\end{array}$ & 'Find out who spends the most time on the computer' (F1) \\
\hline Fun (4) & $\begin{array}{l}\text { Doing something unexpected and 'crazy' with } \\
\text { the toolkit }\end{array}$ & $\begin{array}{l}\text { 'A point-counter whose value controls events at home at ran- } \\
\text { dom: music starts playing etc.' (F1) }\end{array}$ \\
\hline \multicolumn{2}{|c|}{ Non-classifiable items (16) Ideas without a clear form } & 'Learn to have the situation under control' (F2) \\
\hline
\end{tabular}

and F4 were quite active, the members of family 2 almost never used the toolkit without our presence and facilitation. As Table 3 attests, F2 came up with 15 possible uses during visit 2 but then implemented no automation whatsoever. While F2's tenant was active throughout the study he could not use the system to its full extent: he created four automated services, but they could not be used in the study setting. One possible reason for F2's passiveness lies in their initial expectations: the mother had envisioned our toolkit as helping her optimise room-specific temperatures and thereby reduce heating costs. The toolkit was not designed in line with this specific objective, and our system could not be integrated into the house's infrastructure on that level. Since, in contrast, the other three families were active throughout the study, our analysis was based mostly on their data and patterns.

The families differed also with regard to the number of active users. Due to our recruitment principle to enroll only households with children, the number of active users depended on the children's ages. Thus, in F1, F2, and F4, the children took part in the workshops, while F3's children did not. The children's ages had implications also for the automation devised and implemented by the parents, as the following three subsections make clear.

\subsection{What Automation Was Ideated?}

When we analysed and categorised the ideas raised in visit 2's creativity workshop, three high-level categories stood out, each with 1-3 sub-categories (see Table 4). We refer to these as utilitarian, motivational, and social automation. The first two categories show similarities to automation discussed in prior publications (cf. Table 1), with findings related to such matters as saving energy and responding to safety and security issues $[6,12]$.

Social automation entities are more interesting. These have been reported upon only briefly in a survey by Kim et al. [41] and in some discussion by Denefleh et al. [19]. The first sub-category of social automation we found involves resource-sharing: means by which families agree on the use of shared household spaces and equipment. Among the resources receiving focus were the shower time permitted for each family member, bathroom use, and control of the large television screen in the home's lounge. The most commonly envisioned automation was to chain a time-based counter with an alarm sound, to signal when the time allotted to a family member had elapsed.

The second sub-category is related to child-rearing. Parents wished to improve the children's attention to their schoolwork, their rooms' tidiness, and participation in household chores. They also sought better alignment between children's activities and the timetables of others (with swift eating, timely going to bed, etc.). These aims proved popular in the automation actually implementation too, as discussed next.

\subsection{What Automation Was Implemented?}

When the ideas presented above are compared to what families ultimately designed and implemented, interesting differences are evident. Table 5 presents the 14 services that the families implemented and used. The most prominent category in the ideation stage, utilitarian automation, did not predominate at this stage: it accounted for only three automation entities ('Aquarium', 'Sauna is ready', and 'Hypopressive exercise'). Motivational services, in contrast, retained their popularity (with 'Electricity use cutter', 'Computer reward', 'Save water', and 'Study Portuguese'). There was also automation in the 'Other' category (i.e., 'E-treasure-hunt').

Social automation entities, again, stood out. In fact, they represented the most popular category. These often addressed resourcesharing (i.e., 'Clock game' and 'Shower reminder') and, especially, child-rearing (i.e., 'Homework game', 'Sleep-time pacer', 'Dinner 
Table 5: Automation services fully implemented in the study

\begin{tabular}{llc}
\hline F Name: Description & No. of No. of point/ SDT $^{a}$ \\
rules time counters A R C
\end{tabular}

Utilitarian automation:

F3 Sauna is ready: When the sauna is hot enough, a loudspeaker plays a hissing sound.

F4 Hypopressive exercise: When it is time for a core-muscle workout session, a loudspeaker plays a theme.

Motivational automation:

F1 Electricity use cutter: This monitors the use of energy-hungry appliances and awards the family a point if it is under $0.2 \mathrm{kWh} /$ day, with five points earning them a restaurant visit.

F1 Computer reward: If the youngest son uses the computer $2 \mathrm{~h} /$ day or less, he gets two euros.

F4 Save water: Each family member has an NFC token. They push a button when starting to take a shower and push it again when done showering. At the end of the week, the family member who was fastest (and hence used the least water) decides which film to see together.

F4 Study Portuguese: An alarm sounds when it is time to study Portuguese. If the father dedicates at least 15 minutes daily to the lessons, bonus content is unlocked for the next week (e.g., a subtitled film).

Social automation:

F1 Clock game: Points are earned via household chores, with 20 points conferring a week's freedom
from chores.

F3 Shower reminder: When shower-room humidity reaches $80 \%$, the sound of bubbles is played.

F3 Homework game: Children 'sign in' with personal NFC IDs when returning from school. A child who completes the day's homework within 90 minutes and pushes a button accordingly earns 20 points and a fanfare from the loudspeaker, where 100 points is worth a fun activity at the weekend.

F3 Sleep-time pacer: A timer starts when a child turns on the bedside lamp, with the loudspeaker stating that 'reading time' has begun. After 15 minutes, it announces that this time is over.

F4 Dinner in less than 10 mins: A timer starts when a parent pushes a button. If the child finishes dinner within 10 minutes, the parent pushes the button again and the child is awarded a point. If the button is not pushed after 10 minutes, a sound announces that dinner time is over. Having at least four points when Saturday arrives earns the child a fun weekend activity.

F4 Chore rewards: Each child has an NFC tag assigned for his or her daily household chores. If these are done on time, the parents scan the NFC tag to award 10 points. The child with the most points receives a reward at the end of the week (e.g., ice cream).

Other mechanisms:

F4 E-treasure-hunt: The mother assign clues to NFC tags hidden in the house. The children start with the first clue, which is played on a loudspeaker, and they must follow it to find the next NFC tags. If they reach the end of the hunt, they can watch an extra episode of their favourite cartoon show.

\begin{tabular}{|c|c|c|c|c|c|}
\hline Averages & 4.9 & $2.1 / 0.4$ & 3.5 & 2.93 & 3.2 \\
\hline
\end{tabular}

in less than 10 mins', and 'Chore rewards'). Both were prominent sub-categories.

Finally, some of the automation presented in Table 4 was never designed or implemented at all. This was mostly because either the ideas exceeded the technical capacities of the toolkit or corresponding systems proved too ambitious to design in practice. Furthermore, some competitive energy-saving games devised by users did not receive unanimous acceptance from the other members of the family.
Interaction logs show most of these automated services to be composed of several rules that the family members had chained together, either by using rules' outputs as input to other rules or by operating from multiple counters that track time used or points accumulated from events or instances. The largest-scale automation entity, F1's 'Clock game', comprised 17 such rules. All told, 68 rules were used in the 14 automated services that the families described as completed and operational (see Table 5). Besides these, the families created 92 further rules, but they were experimental (not intended 
for implementation), discarded components that were omitted from the final automation, or part of automated services that did not get completed.

Overall, relative to the number of automation ideas raised by the families in the earlier visits (112), the number of automated services actually implemented (14) was small. Family 2 hardly used the system, while F1 and F3 both concentrated on a couple of complex and elaborate systems involving many chained rules and several pointand time-accumulation counters. Their other automated services were mostly side projects. Finally, F4 demonstrated a broad range of actualisation, with elaborate game-style implementations and simpler, largely reminder-oriented ones alike. Hence, the level of system adoption and appropriation that emerged in our study was strikingly different from what Woo and Lim found [64]. In their work, the families used a trigger-action toolkit for only three weeks, without facilitation, yet created an impressive 21 rules per household, on average. Woo and Lim's descriptions of the nature of the resulting automation entities are rather unspecific, however. This restricts any in-depth analysis of the reasons for the divergences between their implementations and those in our study.

\subsection{What Automation Was Needed and Used?}

We are now ready to delve into the primary question of our research: how the families started using the automation and which kinds of automated services proved most successful. From 32 hours of in-situ facilitation and discussion ( 4 workshops $\times 2$ hours each $\times 4$ families), we gained insight into the participants' needs and day-to-day living. Using this background, we analysed how the families appropriated automation - how they started actually using the entities designed and what need they had for them. The rightmost columns in Table 5 present the SDT ratings that we solicited from the participants for their various automated services. These aided in teasing apart and verbalising different aspects of the creations.

Interaction logs revealed that 1,240 triggering events of the total of 2,196 took place within the 14 completed automated services. F1's 'Computer reward' automation produced the highest event count, related to starting (262) and pausing (268) its computer-use timer. Of the events requiring active human interaction (e.g., scanning of an NFC tag by a reader), the trigger in F1's 'Clock game' automation was the most actively used. It accounted for scanning events from three family members, who produced 46,48 , and 49 scans. With these events, household members signalled completion of chores and incremented their count of game points accordingly.

Considering the event logs in conjunction with other information from participants (presented in Table 5) led us to our most significant finding, This was related to the popularity of child-rearingrelated social automation, the only sub-category pattern appearing consistently in every family's data. This automation demonstrated relevance across all age ranges, from young children to the adults deploying it. In fact, F1, F3, and F4 ideated and implemented several automation entities centred on child-rearing, and in visit 4 with F2, the only automation-related topic to receive more discussion was smart-home technologies' general support for saving energy (that family's top priority), even if they did not design and implement any parenting-related automation.
Parents' responsibility for children's personal development was a matter of pervasive relevance for family life, so it eclipsed utilitarian automation. Parents thought about this responsibility daily and were likely to seek technological support for fulfilling it. Chaining of rules and the use of point- and time-accumulation counters were the main enablers for successfully implemented child-rearingrelated automation: the extent of the counters' use in the creation of rules (see Table 5) is testament to their active adoption.

The popularity of automation entities connected with parenting can be ascribed in part to their social nature. Child-rearing-related automated services were 'OK' for everyone in the household. By being game-like and motivational, they did not provoke clashes connected with divergent interests. In comparison, individual-oriented automation was hard to design without bringing a risk of accidental conflicts with other family members' needs and preferences. In F3, for instance, the father often woke up before 6am because of his long commuting distance to work. For a quick cup of coffee before quietly leaving for work, he would have liked to create individual-oriented utilitarian automation that automatically starts the coffee-maker at waking time, but the coffee-maker's noise, which tended to wake his wife, precluded this.

We did not obtain many opinions from the children about automation, because several of them were rather young. We did interview F1's 15- and 17-year-old boys, however. They stated that the family's clock and electricity-cutter automation probably increased relatedness in the family: there was less argument about who has to carry out which chores, and preparation of food became more social because members of the household started saving energy by heating food for the others too, rather than only themselves.

The study uncovered an unexpected challenge that was related to parenting-related automated services, one that our toolkit did not help to address. The services created hierarchies between two sets of users, those designing the automation (the parents) and those forced to use it (the children). Families often masked the power imbalance by framing the automation as a game wherein the latter set of users may earn points and prizes. A second issue arises, though: designing the games such that they remain motivating and sustainable in the long run proved tricky. We discuss the various implications of the hierarchy in more detail in the following section.

\section{DISCUSSION}

By examining what applications for end-user-programmable smarthome toolkits the families would suggest, implement, and actually use, our work diverged from prior research, in which the findings were usually obtained from ideation sessions instead of real-world deployments. The few field-deployment reports identified in our systematic literature review do not discuss the purposes for which smart-home toolkits have been appropriated.

Our work addressing this gap has clearly demonstrated that inventing uses for smart-home toolkits can be highly difficult even for families already showing a keen interest in such technology, possessing the requisite programming skills, and receiving active appropriation support from researchers via in-situ ideation-facilitation workshops.

We find it difficult to imagine better conditions for successful appropriation of smart-home toolkits. This seems to suggest that 
programmable toolkits, in their current design, may seldom be necessary in a family's life, even among families with a priori interest in them and with sufficient competence to start appropriating them.

\subsection{Limitations and Possible Criticisms}

One could contest the conclusions above by asking whether four families and six weeks' experience can justify them. While agreeing that such criticism might be warranted, we would ask why, if four households who, from their profile, should be very receptive to using this technology did not appropriate a well-functioning, robust toolkit naturally, a fifth household would show strong adoption. Also, we find it unlikely that appropriation would have increased significantly after six weeks.

Another objection would be that our toolkit's triggers and actions may not have met participants' expectations: perhaps better integration of the energy-consumption tracking or incorporation of additional sensors (e.g., speech recognition) would have made the appropriation process a success. This is a possibility that we cannot straightforwardly ignore. However, any significant shortcomings in this regard are present in state-of-the-art designs too - more significant integration into household infrastructure is needed before end-user-programmable toolkits providing such possibilities can be offered. Whether future technologies of that sort would really 'do the trick' and enable participants to embrace and appropriate smart-home toolkits remains to be addressed by future research.

\subsection{Improvements to Configurability}

One of our most dramatic findings was that only 14 ideas from the initial 112 reached full implementation and use by the families. As discussed above, insufficient skill with trigger-action logic is unlikely to explain this. A more plausible explanation is that the trigger-action programming model does not suffice and demands too much work for potential users of smart-home automation, notwithstanding several years of development [11, 20, 30, 35, 62]. It may need further work. Although our extensions to the model chaining and counters - were actively used and therefore proved important, they introduced a new challenge for smart-home configuration: in the complex automation entities created by families 1 and 3, the programming model forced the entities' creators to apply very low-level computational concepts. In an interview, F3's father even referred to using point-accumulation counters as makeshift lock variables in some implementations. Even with the benefit of his university degree in computer science, it was difficult to envision large structures layered on top of such low-level building blocks.

Therefore, higher-level configurable programming abstractions would appear necessary for better trigger-action programming. Frequently needed trigger-action combinations should be available as reusable 'templates', to support ease of configuration and good connectivity between devices of different types. Such advances would alleviate the central challenge highlighted by our study: the automated services deemed most successful by the participants were the most complex ones and, accordingly, the most demanding to program. Participants could not foresee that in the ideation stage. We believe this to be one of the major reasons for the general scarcity of actually implemented automation.
The families in our study showed skill and motivation when wrestling with this obstacle, but another hindrance remains: in the end, what should a toolkit be used for? We devote the remainder of the section to addressing this question, with particular attention to the social needs that smart-home toolkits can address.

\subsection{Focusing on Households' Existing Needs}

While a genuine extensive need for smart-home toolkits was far from evident, a positive finding emerged that could inform future research: there are previously unaddressed social patterns in connection with which appropriation can prove successful. Most of the motivational and social automation services presented in Table 5's summary share an aim of either 1) facilitating family members' agreement on joint household practices and use of shared resources or 2) teaching and educating each other about them.

An important distinction that motivational and social automation manifested from utilitarian automation is connected with the needs' obvious and pressing nature. With motivational and social automation services, users sought to resolve and improve the handling of issues in family life that household members thought about, had to face, and (in the case of parenting) even struggled with every day. In this sense, their importance was clearly greater than that of, for instance, convenience-oriented helper-like automation entities, which were typically regarded as optional and 'nice to have'.

Unfortunately, open-ended, freely appropriable toolkits may not speak to their users' specific needs sufficiently at present. Supporting the design of motivational and social automation may require more apparent guidance offered via toolkits' rule-editing features. Responding to this implication also entails deviating from the prevailing mindset, a marketing-driven one wherein smart homes support 'pleasance': lifestyle luxury and aesthetic experiences in domestic settings [59].

We argue that, in place of developing toolkits around the concept of utilitarian and aesthetic ideals, designers should devote more attention to helping users address existing, known issues and struggles in their social household life. Developers could support meeting of social needs by, for example, equipping toolkits with tried and tested 'seed' rules and templates that can accelerate toolkits' adoption for such socially oriented challenges. In our case, with such awareness, we could have pre-populated our toolkit with rule templates oriented toward thorny issues in the fabric of family life. Such templates would have bootstrapped users directly into a higher level of automation design and further inspired ideation for their own automation. We acknowledge that rule templates do exist in some forms, most obviously in IFTTT. However, IFTTT's rules are usually play-oriented and not focused on social needs in family or household life. Being playful and tinkering-oriented, they seem to fail to address the most pressing needs in family life.

It may well be that better identification of user needs lies behind the success of non-user-programmable smart-home technologies, such as security, tele-care, and energy-savings systems. It should not be surprising that these have a more solid market base than user-programmable toolkits; after all, they offer solutions to users' problems. If end-user-programmable toolkits do not do the same, they may remain in the margins, mostly as tinkering tools for technology aficionados. 


\subsection{Attention to Rule-Authors' vs. Users' Needs}

In principle, the bottom-up gamification approach [43] offers users a chance to create games for each other in an egalitarian manner. While this seems a legitimate claim, our study suggests that this outcome may be difficult for families to achieve without tensions.

By this tension we refer to the following problem. Games designed within households may not distribute power equally among their users. The hierarchy that seems to develop between games' creators and the other players [28] has two key implications. Firstly, when drawn into games designed by others, the family's children are in essentially the same position as players in such traditional top-down gamification settings as behaviour-change technologies or workplace gamification: the games' objectives are not set by them but by others (e.g., their parents). This compromises the ideals of bottom-up gamification. The second issue, a subtler one, is a problem similar to one already recognised in studies of multiplayergame communities [56]: implementation of social automation may aid with social matters at home, but if the design and use of such automated services is not a rewarding exercise in itself, excitement about using the toolkit may quickly wane.

Our final recommendation is that future research into smarthome toolkits start looking at two kinds of user experiences: of those who create games for others and of those who participate as players. We suggest, furthermore, that if further studies prove social automation to be a category of smart-home automation with anywhere near the importance evident in our study, toolkits' rule editors could more closely resemble the level editors from the domain of computer gaming, with well-tried ready-made gaming templates and patterns [9] for various social scenarios. This would be an additional reason to investigate the opportunities of programming templates (already mentioned above) as a possible remedy for avoiding low-level programming.

If the creation of automation were itself a more game-like experience, end-user programming for smart homes would be more engaging, and using the rule editors would show less resemblance to wrestling with visual front ends of logic engines or simple flowchart editors. With such adjustments, together with the well-crafted rule templates mentioned above, smart-home toolkits could offer more readily appropriable solutions that mesh with the social fabric of household life and better address users' needs.

\section{CONCLUSION}

Our in-the-wild study uncovered which sorts of smart-home automation a family may ideate, implement, and independently use by means of a programmable toolkit. From our systematic literature review, we believe this paper to be the first comprehensive report on uses articulated in all three of these stages. The findings attest to various challenges that families may encounter in identifying needs for smart-home technologies; however, we also discovered the previously overlooked use category of social automation. Research has not actively attended to social applications because its predominant emphasis has been on smart-home automation employed to utilitarian and aesthetic ends. This contribution could assist in realising the potential for developing smart-home technologies that better respond to the everyday needs of domestic life.

\section{ACKNOWLEDGMENTS}

This work was supported by the Academy of Finland (under grants 286440 and 298879). We thank MX Electrix for the opportunity to use their electricity-meter technology; our colleagues Yves Florack, Lumin Wei, and Ziyi Guo for support with design and implementation; and Iina Kapanen, Liisa Kuparinen, Mikko Särelä, Antti Salovaara (distinct from the author), Friends of the Earth, and the Finnish Nature League for assisting with recruitment for the study.

\section{REFERENCES}

[1] Amazon.com. 2020. Amazon Alexa. Retrieved May 12, 2020 from https://developer. amazon.com/en-US/alexa

[2] Arduino. 2020. Arduino. Retrieved May 12, 2020 from https://www.arduino.cc/

[3] Barbara Rita Barricelli, Fabio Cassano, Daniela Fogli, and Antonio Piccinno. 2019. End-User Development, End-User Programming and End-User Software Engineering: A Systematic Mapping Study. Fournal of Systems and Software 149 (2019), 101-137. https://doi.org/10.1016/j.jss.2018.11.041

[4] Andrea Bellucci, Giulio Jacucci, Veera Kotkavuori, Baris Serim, Imtiaj Ahmed, and Salu Ylirisku. 2015. Extreme Co-design: Prototyping with and by the User for Appropriation of Web-connected Tags. In Proceedings of the International Symposium on End User Development (IS-EUD 2015), Paloma Díaz, Volkmar Pipek, Carmelo Ardito, Carlos Jensen, Ignacio Aedo, and Alexander Boden (Eds.). Springer, Cham, Switzerland, 109-124. https://doi.org/10.1007/978-3-319-18425-88

[5] Andrea Bellucci, Andrea Vianello, Yves Florack, and Giulio Jacucci. 2016. Supporting the Serendipitous Use of Domestic Technologies. IEEE Pervasive Computing 15, 2 (4-6 2016), 16-25. https://doi.org/10.1109/MPRV.2016.26

[6] Andrea Bellucci, Andrea Vianello, Yves Florack, Luana Micallef, and Giulio Jacucci. 2019. Augmenting Objects at Home Through Programmable Sensor Tokens: A Design Journey. International fournal of Human-Computer Studies 122 (2019), 211-231. https://doi.org/10.1016/j.ijhcs.2018.09.002

[7] Arne Berger, Aloha Hufana Ambe, Alessandro Soro, Dries De Roeck, and Margot Brereton. 2019. The Stories People Tell About the Home Through IoT Toolkits. In Proceedings of the 2019 on Designing Interactive Systems Conference (DIS 2019). ACM Press, New York, NY, 7-19. https://doi.org/10.1145/3322276.3322308

[8] Arne Berger, William Odom, Michael Storz, Andreas Bischof, Albrecht Kurze, and Eva Hornecker. 2019. The Inflatable Cat: Idiosyncratic Ideation of Smart Objects for the Home. In Proceedings of the 2019 CHI Conference on Human Factors in Computing Systems (CHI 2019). ACM Press, New York, NY, 1-12. https: //doi.org/10.1145/3290605.3300631

[9] Staffan Björk and Jussi Holopainen. 2004. Patterns in Game Design. Charles River Media, Needham Heights, MA.

[10] Jacky Bourgeois, Janet van der Linden, Gerd Kortuem, Blaine A. Price, and Christopher Rimmer. 2014. Conversations with My Washing Machine: An in-theWild Study of Demand Shifting with Self-Generated Energy. In Proceedings of the 2014 ACM International foint Conference on Pervasive and Ubiquitous Computing (Ubicomp 2014). ACM Press, New York, NY, 459-470. https://doi.org/10.1145/ 2632048.2632106

[11] Will Brackenbury, Abhimanyu Deora, Jillian Ritchey, Jason Vallee, Weijia He, Guan Wang, Michael L. Littman, and Blase Ur. 2019. How Users Interpret Bugs in Trigger-Action Programming. In Proceedings of the 2019 CHI Conference on Human Factors in Computing Systems (CHI 2019). ACM Press, New York, NY, 1-12. https://doi.org/10.1145/3290605.3300782

[12] Julia Brich, Marcel Walch, Michael Rietzler, Michael Weber, and Florian Schaub. 2017. Exploring End User Programming Needs in Home Automation. ACM Transactions on Computer-Human Interaction 24, 2 (2017), 11:1-11:35. https: //doi.org/10.1145/3057858

[13] A.J. Bernheim Brush, Bongshin Lee, Ratul Mahajan, Sharad Agarwal, Stefan Saroiu, and Colin Dixon. 2011. Home Automation in the Wild: Challenges and Opportunities. In Proceedings of the SIGCHI Conference on Human Factors in Computing Systems (CHI 2011). ACM Press, New York, NY, 2115-2124. https: //doi.org/10.1145/1978942.1979249

[14] Vic Callaghan, Jeannette Chin, Victor Zamudio, Graham Clarke, Anuroop Shahi, and Michael Gardner. 2008. Domestic Pervasive Information Systems: End-User Programming of Digital Homes. In Pervasive Information Systems, Panos E Kourouthanassis and George M Giaglis (Eds.). Vol. 1. M. E. Sharpe, New York, Chapter 5, 129-149.

[15] J. Cao, K. Rector, T. H. Park, S. D. Fleming, M. Burnett, and S. Wiedenbeck. 2010. A Debugging Perspective on End-User Mashup Programming. In 2010 IEEE Symposium on Visual Languages and Human-Centric Computing (VLHCC 2010). IEEE Computer Society, New York, NY, 149-156. https://doi.org/10.1109/VLHCC. 2010.29

[16] Fulvio Corno, Luigi De Russis, and Alberto Monge Roffarello. 2019. Empowering End Users in Debugging Trigger-Action Rules. In Proceedings of the 2019 CHI Conference on Human Factors in Computing Systems (CHI 2019). ACM Press, New 
York, NY, 1-13. https://doi.org/10.1145/3290605.3300618

[17] J. Coutaz and J. L. Crowley. 2016. A First-Person Experience with End-User Development for Smart Homes. IEEE Pervasive Computing 15, 2 (2016), 26-39. https://doi.org/10.1109/MPRV.2016.24

[18] Luigi De Russis and Fulvio Corno. 2015. HomeRules: A Tangible End-User Programming Interface for Smart Homes. In Proceedings of the 33rd Annual ACM Conference Extended Abstracts on Human Factors in Computing Systems (CHI EA 2015). ACM Press, New York, NY, 2109-2114. https://doi.org/10.1145/2702613. 2732795

[19] Teresa Denefleh, Arne Berger, Albrecht Kurze, Andreas Bischof, and Christopher Frauenberger. 2019. Sensorstation: Exploring Simple Sensor Data in the Context of a Shared Apartment. In Proceedings of the 2019 on Designing Interactive Systems Conference (DIS 2019), Steve Harrison, Shaowen Bardzell, Carman Neustaedter and Deborah Tatar (Eds.). ACM Press, New York, NY, 683-695. https://doi.org/ $10.1145 / 3322276.3322309$

[20] Giuseppe Desolda, Carmelo Ardito, and Maristella Matera. 2017. Empowering End Users to Customize Their Smart Environments: Model, Composition Paradigms, and Domain-Specific Tools. ACM Transactions on Computer-Human Interaction 24, 2 (2017), 12:1-12:52. https://doi.org/10.1145/3057859

[21] Clive Edwards. 2005. Turning Houses into Homes: A History of the Retailing and Consumption of Domestic Furnishings. Routledge, London, UK. https://doi.org/ 10.4324/9781315235516

[22] Daniela Fogli, Rosa Lanzilotti, Antonio Piccinno, and Paolo Tosi. 2016. AmI@Home: A Game-Based Collaborative System for Smart Home Configuration. In Proceedings of the International Working Conference on Advanced Visual Interfaces (AVI 2016). ACM Press, New York, NY, 308-309. https: //doi.org/10.1145/2909132.2926083

[23] Raspberry Pi Foundation. 2020. Raspberry Pi. Retrieved May 12, 2020 from https://raspberrypi.org

[24] Joep Frens, Mathias Funk, Bastiaan van Hout, and Joep Le Blanc. 2018. Designing the IoT Sandbox. In Proceedings of the 2018 Designing Interactive Systems Conference (DIS 2018). ACM Press, New York, NY, 341-354. https://doi.org/10.1145/ 3196709.3196815

[25] Mathias Funk, Lin-Lin Chen, Shao-Wen Yang, and Yen-Kuang Chen. 2018. Addressing the Need to Capture Scenarios, Intentions and Preferences: Interactive Intentional Programming in the Smart Home. International fournal of Design 12, 1 (2018), 53-66.

[26] Bill Gaver. 2002. Designing for Homo Ludens. i3 Magazine (2002).

[27] William Gaver, John Bowers, Tobie Kerridge, Andy Boucher, and Nadine Jarvis. 2009. Anatomy of a Failure: How We Knew when Our Design Went Wrong, and What We Learned from It. In Proceedings of the International Conference on Human Factors in Computing Systems (CHI 2009). ACM Press, New York, NY, 2213-2222.

[28] Christine Geeng and Franziska Roesner. 2019. Who's In Control? Interactions in Multi-User Smart Homesn Multi-User Smart Homes. In Proceedings of the 2019 CHI Conference on Human Factors in Computing Systems (CHI 2019). ACM Press, New York, NY, 1-13. https://doi.org/10.1145/3290605.3300498

[29] H. Ghayvat, J. Liu, S. C. Mukhopadhyay, and X. Gui. 2015. Wellness Sensor Networks: A Proposal and Implementation for Smart Home for Assisted Living. IEEE Sensors fournal 15, 12 (2015), 7341-7348. https://doi.org/10.1109/JSEN.2015. 2475626

[30] Giuseppe Ghiani, Marco Manca, Fabio Paternò, and Carmen Santoro. 2017. Personalization of Context-Dependent Applications Through Trigger-Action Rules. ACM Transactions on Computer-Human Interaction 24, 2 (2017), 14:1-14:33 https://doi.org/10.1145/3057861

[31] Google. 2020. NEST Learning Thermostat. Retrieved May 12, 2020 from https: //store.google.com/en/product/nest_learning_thermostat_3rd_gen

[32] Sergio Tirado Herrero, Larissa Nicholls, and Yolande Strengers. 2018. Smart Home Technologies in Everyday Life: Do They Address Key Energy Challenges in Households? Current Opinion in Environmental Sustainability 31 (2018), 65-70. https://doi.org/10.1016/j.cosust.2017.12.001

[33] Donna L. Hoffman and Thomas P. Novak. 2017. Consumer and Object Experience in the Internet of Things: An Assemblage Theory Approach. Journal of Consumer Research 44, 6 (2017), 1178-1204. https://doi.org/10.1093/jcr/ucx105

[34] Steven Houben, Connie Golsteijn, Sarah Gallacher, Rose Johnson, Saskia Bakker Nicolai Marquardt, Licia Capra, and Yvonne Rogers. 2016. Physikit: Data Engagement Through Physical Ambient Visualizations in the Home. In Proceedings of the 2016 CHI Conference on Human Factors in Computing Systems (CHI 2016) ACM Press, New York, NY, 1608-1619. https://doi.org/10.1145/2858036.2858059

[35] Justin Huang and Maya Cakmak. 2015. Supporting Mental Model Accuracy in Trigger-Action Programming. In Proceedings of the 2015 ACM International foint Conference on Pervasive and Ubiquitous Computing (Ubicomp 2015). ACM Press, New York, NY, 215-225. https://doi.org/10.1145/2750858.2805830

[36] IFTTT Inc. 2020. IFTTT. Retrieved May 12, 2020 from https://ifttt.com/

[37] Texas Instruments Incorporated. 2020. SimpleLink multi-standard CC2650 SensorTag kit reference design. Retrieved May 12, 2020 from http://www.ti.com/tool/ TIDC-CC2650STK-SENSORTAG
[38] Timo Jakobi, Corinna Ogonowski, Nico Castelli, Gunnar Stevens, and Volker Wulf. 2017. The Catch(Es) with Smart Home: Experiences of a Living Lab Field Study. In Proceedings of the 2017 CHI Conference on Human Factors in Computing Systems (CHI 2017). ACM Press, New York, NY, 1620-1633. https://doi.org/10. $1145 / 3025453.3025799$

[39] Timo Jakobi, Gunnar Stevens, Nico Castelli, Corinna Ogonowski, Florian Schaub, Nils Vindice, Dave Randall, Peter Tolmie, and Volker Wulf. 2018. Evolving Needs in IoT Control and Accountability: A Longitudinal Study on Smart Home Intelligibility. Proceedings of the ACM on Interactive, Mobile, Wearable and Ubiquitous Technologies (IMWUT 2018) 2, 4, Article 171 (2018), 28 pages. https://doi.org/10.1145/3287049

[40] Rikke Hagensby Jensen, Yolande Strengers, Jesper Kjeldskov, Larissa Nicholls, and Mikael B. Skov. 2018. Designing the Desirable Smart Home: A Study of Household Experiences and Energy Consumption Impacts. In Proceedings of the 2018 CHI Conference on Human Factors in Computing Systems (CHI 2018). ACM Press, New York, NY, 1-14. https://doi.org/10.1145/3173574.3173578

[41] Ji Eun Kim, Xiangmin Fan, and Daniel Mosse. 2017. Empowering End Users for Social Internet of Things. In Proceedings of the Second International Conference on Internet-of-Things Design and Implementation (IoTDI 2017). ACM Press, New York, NY, 71-82. https://doi.org/10.1145/3054977.3054987

[42] Andrew J. Ko, Robin Abraham, Laura Beckwith, Alan Blackwell, Margaret Burnett, Martin Erwig, Chris Scaffidi, Joseph Lawrance, Henry Lieberman, Brad Myers, Mary Beth Rosson, Gregg Rothermel, Mary Shaw, and Susan Wiedenbeck. 2011. The State of the Art in End-User Software Engineering. Comput. Surveys 43, 3 (2011), 21:1-21:44. https://doi.org/10.1145/1922649.1922658

[43] Pascal Lessel, Maximilian Altmeyer, Marc Müller, Christian Wolff, and Antonio Krüger. 2016. "Don't Whip Me With Your Games" - Investigating "Bottom-Up" Gamification. In Proceedings of the 2016 SIGCHI Conference on Human Factors in Computing Systems (CHI 2016), Jofish Kaye, Allison Druin, Cliff Lampe, Dan Morris, and Juan Pablo Hourcade (Eds.). ACM Press, New York, NY, 2026-2037. https://doi.org/10.1145/2858036.2858463

[44] Sarah Mennicken and Elaine M. Huang. 2012. Hacking the Natural Habitat: An In-the-Wild Study of Smart Homes, Their Development, and the People Who Live in Them. In Pervasive Computing, Judy Kay, Paul Lukowicz, Hideyuki Tokuda, Patrick Olivier, and Antonio Krüger (Eds.). Springer, Berlin, Heidelberg, 143-160. https://doi.org/10.1007/978-3-642-31205-2_10

[45] Sarah Mennicken, Jo Vermeulen, and Elaine M. Huang. 2014. From Today's Augmented Houses to Tomorrow's Smart Homes: New Directions for Home Automation Research. In Proceedings of the 2014 ACM International foint Conference on Pervasive and Ubiquitous Computing (Ubicomp 2014). ACM Press, New York, NY, 105-115. https://doi.org/10.1145/2632048.2636076

[46] Xianghang Mi, Feng Qian, Ying Zhang, and XiaoFeng Wang. 2017. An Empirical Characterization of IFTTT: Ecosystem, Usage, and Performance. In Proceedings of the 2017 Internet Measurement Conference (IMC 2017). ACM Press, New York, NY, 398-404. https://doi.org/10.1145/3131365.3131369

[47] David Moher, Alessandro Liberati, Jennifer Tetzlaff, Douglas G. Altman, and The PRISMA Group. 2009. Preferred Reporting Items for Systematic Reviews and Meta-Analyses: The PRISMA Statement. PLoS Medicine 6, 7 (2009). https: //doi.org/10.1371/journal.pmed.1000097

[48] Tommy Nilsson, Andy Crabtree, Joel Fischer, and Boriana Koleva. 2019. Breaching the Future: Understanding Human Challenges of Autonomous Systems for the Home. Personal and Ubiquitous Computing 23, 2 (2019), 287-307. https://doi.org/ 10.1007/s00779-019-01210-7

[49] Fabio Paternò and Carmen Santoro. 2019. End-User Development for Personalizing Applications, Things, and Robots. International fournal of Human-Computer Studies 131 (2019), 120-130. https://doi.org/10.1016/j.ijhcs.2019.06.002

[50] Philips. 2020. Philips Hue. Retrieved May 12, 2020 from https://meethue.com

[51] Johnmarshall Reeve. 2000. Understanding Motivation and Emotion (3 ed.). John Wiley \& Sons, New York, NY.

[52] Rosslin John Robles and Tai hoon Kim. 2010. A Review on Security in Smart Home Development. International fournal of Advanced Science and Technology 15 (2010), 13-22.

[53] Tom Rodden and Steve Benford. 2003. The Evolution of Buildings and Implications for the Design of Ubiquitous Domestic Environments. In Proceedings of the SIGCHI Conference on Human Factors in Computing Systems (CHI 2003). ACM Press, New York, NY, 9-16. https://doi.org/10.1145/642611.642615

[54] Richard M. Ryan and Edward L. Deci. 2000. Self-Determination Theory and the Facilitation of Intrinsic Motivation, Social Development, and Well-Being. American Psychologist 55, 1 (2000), 68-78.

[55] Fibar Group S.A. 2020. Fibaro Wall Plug. Retrieved May 12, 2020 from https: //www.fibaro.com/en/products/wall-plug/

[56] Antti Salovaara, Mikael Johnson, Kalle Toiskallio, Sauli Tiitta, and Marko Turpeinen. 2005. Playmakers in Multiplayer Game Communities: Their Importance and Motivations for Participation. In Proceedings of the 2005 ACM SIGCHI International Conference on Advances in Computer Entertainment Technology (ACE 2005). ACM Press, New York, NY, 334-337. https://doi.org/10.1145/1178477. 1178540 
[57] Corina Sas and Carman Neustaedter. 2017. Exploring DIY Practices of Complex Home Technologies. ACM Transactions on Computer-Human Interaction 24, 2 (2017), 16:1-16:29. https://doi.org/10.1145/3057863

[58] Biljana L. Risteska Stojkoska and Kire V. Trivodaliev. 2017. A Review of Internet of Things for Smart Home: Challenges and Solutions. Fournal of Cleaner Production 140 (2017), 1454-1464. https://doi.org/10.1016/j.jclepro.2016.10.006

[59] Yolande Strengers, Mike Hazas, Larissa Nicholls, Jesper Kjeldskov, and Mikael B. Skov. 2020. Pursuing Pleasance: Interrogating Energy-Intensive Visions for the Smart Home. International fournal of Human-Computer Studies 136 (2020), 1-14. https://doi.org/10.1016/j.ijhcs.2019.102379

[60] Leila Takayama, Caroline Pantofaru, David Robson, Bianca Soto, and Michael Barry. 2012. Making Technology Homey: Finding Sources of Satisfaction and Meaning in Home Automation. In Proceedings of the 2012 ACM Conference on Ubiquitous Computing (Ubicomp 2012). ACM Press, New York, NY, 511-520. https: //doi.org/10.1145/2370216.2370292

[61] Jordan Tewell, Dympna O’Sullivan, Neil Maiden, James Lockerbie, and Simone Stumpf. 2019. Monitoring Meaningful Activities Using Small Low-Cost Devices in a Smart Home. Personal and Ubiquitous Computing 23, 2 (2019), 339-357. https://doi.org/10.1007/s00779-019-01223-2

[62] Blase Ur, Elyse McManus, Melwyn Pak Yong Ho, and Michael L. Littman. 2014 Practical Trigger-Action Programming in the Smart Home. In Proceedings of the
SIGCHI Conference on Human Factors in Computing (CHI 2014). ACM Press, New York, NY, 803-812. https://doi.org/10.1145/2556288.2557420

[63] Blase Ur, Melwyn Pak Yong Ho, Stephen Brawner, Jiyun Lee, Sarah Mennicken, Noah Picard, Diane Schulze, and Michael L. Littman. 2016. Trigger-Action Programming in the Wild: An Analysis of 200,000 IFTTT Recipes. In Proceedings of the 2016 CHI Conference on Human Factors in Computing Systems (CHI 2016). ACM Press, New York, NY, 3227-3231. https://doi.org/10.1145/2858036.2858556

[64] Jong-bum Woo and Youn-kyung Lim. 2015. User Experience in Do-It-YourselfStyle Smart Homes. In Proceedings of the 2015 ACM International foint Conference on Pervasive and Ubiquitous Computing (Ubicomp 2015). ACM Press, New York, NY, 779-790. https://doi.org/10.1145/2750858.2806063

[65] Allison Woodruff, Sally Augustin, and Brooke Foucault. 2007. Sabbath Day Home Automation: "It's Like Mixing Technology and Religion". In Proceedings of the SIGCHI Conference on Human Factors in Computing Systems (CHI 2007). ACM Press, New York, NY, 527-536. https://doi.org/10.1145/1240624.1240710

[66] Volker Wulf, Volkmar Pipek, and Markus Won. 2008. Component-Based Tailorability: Enabling Highly Flexible Software Applications. International fournal of Human-Computer Studies 66, 1 (2008), 1-22. https://doi.org/10.1016/j.ijhcs. 2007.08.007 